\title{
Bias in cohort-based comparisons of immigrants' health outcomes between countries: a simulation study
}

\author{
Odile Sauzet ${ }^{1,2^{*}}$ id and Oliver Razum ${ }^{1}$
}

\begin{abstract}
Background: Cohort-type data are increasingly used to compare health outcomes of immigrants between countries, e.g. to assess the effects of different national integration policies. In such international comparisons, small differences in cardiovascular diseases risk or mortality rates have been interpreted as showing effects of different policies. We conjecture that cohort-type data sets available for such comparisons might not provide unbiased relative risk estimates between countries because of differentials in migration patterns occurring before the cohorts are being observed.

Method: Two simulation studies were performed to assess whether comparisons are biased if there are differences in 1. the way migrants arrived in the host countries, i.e. in a wave or continuously; 2 . the effects on health of exposure to the host country; or 3., patterns of return-migration before a cohort is recruited. In the first simulation cardiovascular disease was the outcome and immortality in the second. Bias was evaluated using a Cox regression model adjusted for age and other dependant variables.

Results: Comparing populations from wave vs. continuous migration may lead to bias only if the duration of stay has a dose-response effect (increase in simulated cardiovascular disease risk by $5 \%$ every 5 years vs. no risk: hazard-ratio $1.20(0.15)$; by $10 \%$ every 5 years: $1.47(0.14))$. Differentials in return-migration patterns lead to bias in mortality rate ratios (MRR). The direction (under- or overestimation) and size of the bias depends on the model (MRR from 0.92(0.01) to $1.09(0.01))$.

Conclusion: The order of magnitude of the effects interpreted as due to integration policies in the literature is the same as the bias in our simulations. Future studies need to take into account duration and relevance of exposure and return-migration to make valid inferences about the effects of integration policies on the health of immigrants.
\end{abstract}

Keywords: Immigrant health, Integration policies, Return-migration, Left truncation

\section{Background}

The social, political, and economical context in which immigrant people live may be affecting their health. International comparisons can help assess how the national context may influence health outcomes. Such studies comparing majority populations have been done by Mackenbach et al. [1] to investigate contextual determinants of health inequalities such as educational opportunities or income distribution. Recently, similar

\footnotetext{
* Correspondence: odile.sauzet@uni-bielefeld.de

'Department of Epidemiology \& International Public Health, Bielefeld School of Public Health (BiSPH), Bielefeld University, P.O. Box 1001 31, 33501 Bielefeld, Germany

${ }^{2}$ Center for Statistics, Bielefeld University, P.O. Box 1001 31, 33501 Bielefeld, Germany
}

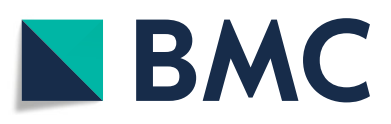

(0) The Author(s). 2019 Open Access This article is distributed under the terms of the Creative Commons Attribution 4.0 International License (http://creativecommons.org/licenses/by/4.0/), which permits unrestricted use, distribution, and reproduction in any medium, provided you give appropriate credit to the original author(s) and the source, provide a link to the Creative Commons license, and indicate if changes were made. The Creative Commons Public Domain Dedication waiver (http://creativecommons.org/publicdomain/zero/1.0/) applies to the data made available in this article, unless otherwise stated. approaches have been used in attempts to show the effect of different national policies on the health of immigrant populations.

While Bhopal et al. merely aimed to show that comparing registry-derived mortality rates by ethnicity groups due to cardiovascular diseases across countries was feasible [2], Malmusi [3] concluded from similar cross-sectional data that immigrants living in assimilationist European countries had a higher risk of poor health than those living in multicultural countries (prevalence ratio 1.21, 95\% confidence interval (1.03, 1.41)). Ikram et al. [4] compared the effect of integration policies on the mortality of immigrants using an open cohort design. With a mortality rate ratio (MMR) of 
1.92 (95\% confidence interval $(1.74,2.13)$ ) for Turkishborn men in Denmark vs. the Netherlands, two countries with different integration policies, the authors concluded that "macro-level policy context may influence immigrants' mortality". The assumption underlying such interpretations is that the population data available for comparison provide unbiased relative risk estimates between countries. This assumption may not be met if there were differentials in migration patterns occurring before the populations are being observed, and this is independent of the study design used. For example, if return-migration took place in both populations but following different patterns in term of association with health outcomes, this would strongly limit the interpretation of differences in health outcomes as an effect of national integration policies.

Immigrant populations considered for international comparisons may be difficult to compare across countries because of different mechanisms leading to the constitution of these groups. In Europe, some immigrant populations have arrived in a wave (e.g. Turkish "guest workers" in Germany 1960-1973 after which recruitment was stopped; refugee migration due to conflicts) or continuously (e.g. immigrants from the Indian Subcontinent in Great Britain) [5]. Moreover, at the time of recruitment into, say, a cohort, some immigrants who would have been eligible may no longer be available as they have returned to their country of origin for personal reasons. These may comprise health (Handlos et al. [6] have shown that for elderly Bosnian refugees, physical and mental well-being were factors driving the decision to return-migrate; Razum et al. [7] found that interactions between perceived health status and economic success explained return migration), or the belief that they can make better use of their qualifications there [8,9]. This will affect international comparisons if returnmigration is differential with regard to the risk of the outcome under study.

In this work we consider three potential sources of bias in international comparisons of health outcomes of immigrants due to events occurring before the recruitment into a cohort took place, or data are otherwise constituted:

\section{Comparing cohorts from migration wave vs. from continuous migration}

A population that has arrived in a wave, with immigration ending at $t_{1}$ e.g. due to a recruitment stop or the termination of a conflict in the country of origin, is available for recruitment into a cohort at a later point in time $t_{2}$ only in a non-representative way. The group still available for recruitment at $t_{2}$ represents a depleted picture of a closed cohort, having lost some of its members for health-related reasons between $t_{1}$ and $t_{2}$. Continuous migration, in contrast, provides a population of immigrants with a larger span of arrivals and returns, offering the characteristics of an open or dynamic cohort [10]. This is our first potential source of bias if the populations compared are issued from different types of migration.

\section{Differential in duration of exposure to the host country between populations}

The populations compared may have had different durations of exposure to the integration policy of their respective host country - while under observation as well as in historical periods preceding the recruitment. If policies indeed have an effect on health it should show some form of dose-response relationship depending on the duration of exposure, including during time spent in the host country before being recruited into the study (exposure assessment may be further complicated by a change in the type of policy within a country). Unaccounted differentials in time of exposure constitute a second potential source of bias in comparisons between countries.

\section{Differential in selective return-migration between populations}

Return-migration, when it is selective, leads to biased estimates of morbidity or mortality rates. For example, the "salmon-effect" hypothesis postulates that migrants with deteriorating health preferentially return to their country of origin [11]. This source of bias has been forwarded (and subsequently rejected [12]) as an explanation of the mortality advantage that the Latino population in the USA seems to enjoy. More recent research by Norredam and colleagues [13] has shown that the risk of returnmigration reduced with increased severity of disease. This indicates that reasons for return-migration might be complex but not independent from the conditions in the host country as well as in the country of origin. Therefore, patterns of return-migration are likely to vary between host countries, thus creating a differential in return migration between the countries compared. Other critical life periods may be associated with different reasons for selective return-migration: for example highly qualified (and thus often particularly healthy) immigrants who see opportunities in their country of origin $[8,9]$.

Because the mechanisms leading to selective returnmigration are directly (e.g. old age) or indirectly (e.g. qualification through a social gradient for health outcomes) linked to health, ignoring them will lead to biased estimates of mortality. Only if the mechanisms leading to return-migration were constant across countries and immigrant populations between which policies 
are compared, this bias would disappear with relative mortality rates.

With selective return-migration some immigrants are no longer available at the time when, for example, a cohort is recruited. This phenomenon is called lefttruncation [14]. A similar cause of left-truncation has been described for occupational cohorts, leading to an underestimation of exposure effects [15]. Cain et al. gave a more general description of bias due to left-truncation in epidemiology [16].

Using two simulation studies we investigate how differentials between countries in the above-mentioned factors at work before the immigrants are being observed may lead to bias in international comparisons of immigrant health outcomes used to analyse the effect of different national integration policies (Fig. 1). Using simulation studies enables the generation of hypothetical cohort data which differ only in the phenomena of interest (here: pattern of migration, duration of exposure to the host country, or return migration). For this purpose we simulate data according to a cohort study design but stress that the issues raised will also apply to some cross-sectional comparisons. The first simulation study looks into bias due to wave/continuous migration (1) and differentials in duration of exposure (2) simulating cardiovascular diseases. A second simulation study shows how some simple hypotheses about differentials in selective return-migration (3) can lead to bias in mortality rate ratio estimates between populations with and without return-migration.

\section{Method}

\section{Migrations waves vs. continuous migration}

The aim of the first simulation is to show if factors associated with different arrival patterns (migration waves vs. continuous migration) could lead to bias in international comparisons. For illustration purposes, the outcome simulated is cardiovascular diseases (CVD) with the stochastic model being shown below. We compare two hypothetical cohorts (Cohort 1 and Cohort 2) of immigrants, one which arrived in the host country during a limited 5-year duration which ended 15 years before recruitment into the cohort and an otherwise equal cohort but which migrated at any time during the 20 years preceding the recruitment of the cohort. The ages at migration and arrivals are uniformly distributed in the interval 20-50 years and across the migration period, respectively (5 years for wave migration and 20 years for continuous migration).

In our model, members of the immigrant population of both cohorts may either die or return-migrate before recruitment, in which case they cannot be recruited into a cohort. For Cohort 1, the duration of exposure to the host country is at least 15 years, whereas for Cohort 2 this duration can be briefer. For this simulation, the rate of death/return-migration is the same for both cohorts. Cardiovascular disease and death/return-migration are modelled using a Weibull distribution for the baseline hazard $h_{0}(t)$ chosen to provide a sufficient number of cases. The population without disease are those without CVD before age 84. A higher hazard of death/return-migration is modelled for those who will suffer from CVD in the future. The simulated sample sizes before any censoring were 2000, 5000 and 10000 . The total number of recruited participants in the cohort will depend on the hazard of return migration, which has been set to $1.2,1$ and 0.8 .

The two hypothetical cohorts are recruited exactly 20 years after the first migration. The cohorts then consist of all those immigrants who did not either have CVD before recruitment of the cohort or died/return-migrated. Immigrants are observed for 5 years. Those who have no event during this period are censored after 5 years. Those who die/return-migrate during this period are censored at the time of event.

The bias due to comparing health outcomes between cohorts with migration waves vs. continuous migration was evaluated using a Cox regression model with cohort (continuous migration as reference) and age as dependent variables at the end of the observation period, i.e. 5 years after recruitment.

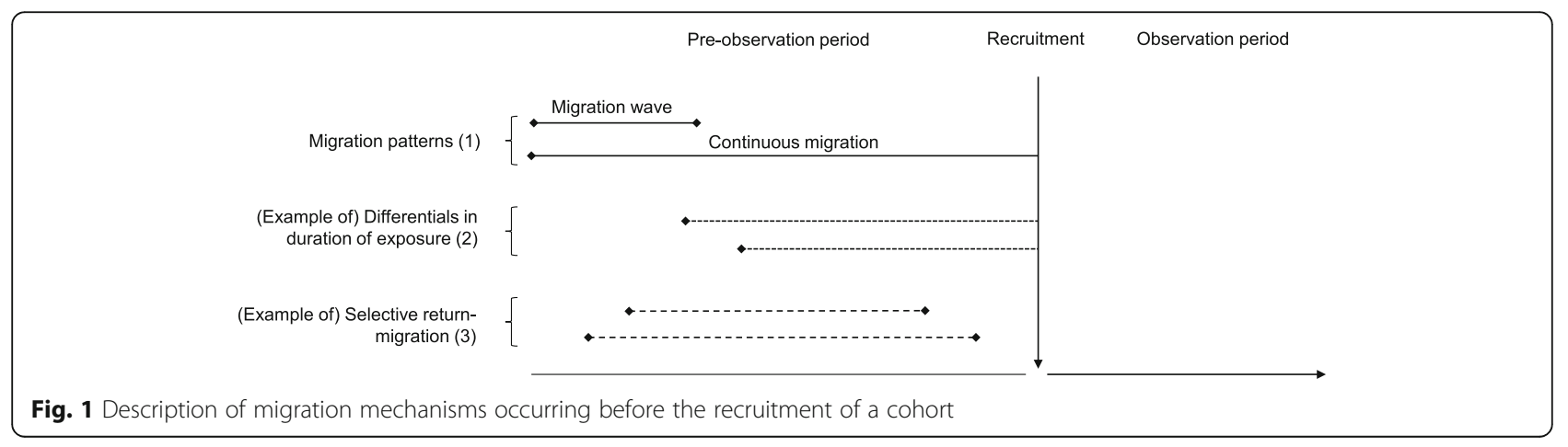


Given the models above, the simulations run as follow:

1. Age at migration, year of migration for Cohort 1 and 2, and age at recruitment are obtained.

2. Age with CVD is obtained. All cohort members with age above 85 years are censored at age 85 .

3. Age at remigration/death is obtained.

4. It is evaluated whether death/return-migration occurred before, during or after the cohort observation time.

5. Hazard of CVD between the two cohorts is obtained using a Cox regression model adjusted for age at recruitment.

\section{Duration of exposure to the host country}

Using the same simulation scenarios as above, we investigate the possibility of bias due to ignoring the differentials in duration of exposure. We use a proportional hazard model for the dependence of the hazard of CVD on the duration. The scale used is 5-year exposure to the host country so that the hazard is given by

$$
\mathrm{h}(\mathrm{t})=\mathrm{h}_{0}(\mathrm{t}) \exp (\log () *(\text { exposure duration }))
$$

The hazard of CVD increases by $\beta$ every 5 years of exposure. Values for $\beta$ range from 0 to 0.2 (see Table 1).

\section{Selective return-migration}

In a separate simulation model we concentrate on differentials in selective return-migration patterns between cohorts. We compare two simulated cohorts: one in which return-migration occurred, and one in which none occurred before recruitment using a stochastic process described below. We also modelled covariates which influence the probability of return-migration at certain period of life.

Education is obtained using a multinomial distribution with three values with probabilities $0.5,0.3$ and 0.2 respectively. Income is obtained using a multinomial distribution with five values with probabilities 0.2 each to reflect quintiles of the distribution of incomes.

The simulated populations are obtained using a survival model for which each observation is defined by the age of death. Death is modelled to obtain estimates based on a real population (here the German one [17]) using a mixture of two Weibull distributions. We set the respective weights for death in infancy $(0.006)$ and death in later life (0.994) so that they reflect the real life table. The baseline survival function is given by

$$
\mathrm{S}_{0}(\mathrm{t})=0.006 \exp (-(\mathrm{t} / 80) * 0.2)+0.994 \exp (-(\mathrm{t} / 80) * 7)
$$

The effects of covariates on the age of death compared to income quintile of 1 or 2 are provided by adding survival time according to the following normal distribution with mean given below and standard deviation of 2 years:

- education level $=3$ and income quintile $=3$ increases life by an average of 8 years;

- education level $=3$ and income quintile $=4$ increases life by an average of 12 years;

- education level $=3$ and income quintile $=5$ increases life by an average of 14 years;

- education level $<3$ and income quintile $=4$ increases life by an average of 8 years;

- education level $<3$ and income quintile $=5$ increases life by an average of 11 years.

We chose three critical periods for return-migration: between the ages of 25 and 35 (end of studies, beginning of career), between the age of 63 and 67 (retirement) and due to bad health 3 years before death occurs (results would be identical if we modelled that bad health reduces the chance of return-migration; important is a differential between the compared cohorts). We chose four models where the probabilities of return-migration during the three critical periods vary (see Additional file 1: Table S1).

- Model 1: Return-migration at the first critical period with probability increasing with education level and income. Here it is assumed that with increased socio-economic success in the host country, migrants will see and use opportunities in the country of origin.

- Model 2: Return-migration at the second critical period with probability decreasing with income. Here, retired migrants will have an increased probability to return to their country of origin if they are less well-off.

- Model 3: Return-migration with probability increasing with education and income for the first critical period and increasing with income only for the second. The probability of return-migration due to bad health is non-zero only for the highest income quintile. This model reflects Model 1 for younger migrants; for older migrants, higher income as associated to ill health leads to a higher probability of return-migration.

- Model 4: Same as Model 3 but all cohort members have the same probability of return-migration due to ill health.

Data were simulated as above for nine 5-year age groups from 40 to 89 years, with 2800 observations each (total of 25200 observation). Observation time in a given age group starts at the lower value $a$ of the age group. Persons are part of the population at risk (of 
Table 1 Bias due to ignoring the exposure duration to the host country and type of migration expressed as the mean hazard ratio (HR) and standard deviation (SD) for risk of CVD between a cohort with continuous migration (Cohort 2, reference) and a cohort with a one-wave migration for various hazard of return migration (Cohort 1). Mean sample sizes (ss) for each cohort are given for varying return migration (R-M) hazards

\begin{tabular}{|c|c|c|c|c|c|c|c|c|c|c|c|c|c|c|c|c|c|c|c|}
\hline \multicolumn{10}{|c|}{ No risk of CVD due to exposure } & \multicolumn{10}{|c|}{ 5-year exposure increases risk of CVD by $2.5 \%$} \\
\hline \multicolumn{20}{|l|}{ Mean values } \\
\hline $\begin{array}{l}\text { R-M } \\
\text { hazard }\end{array}$ & 1.20 & 1.20 & 1.20 & 1.00 & 1.00 & 1.00 & 0.80 & 0.80 & 0.80 & $\begin{array}{l}\text { R-M } \\
\text { hazard }\end{array}$ & 1.20 & 1.20 & 1.20 & 1.00 & 1.00 & 1.00 & 0.80 & 0.80 & 0.80 \\
\hline $\begin{array}{l}\text { SS Cohort } \\
1\end{array}$ & 1491 & 3729 & 7459 & 1454 & 3634 & 7269 & 1403 & 3509 & 7017 & $\begin{array}{l}\text { SS Cohort } \\
1\end{array}$ & 1436 & 3589 & 7178 & 1407 & 3516 & 7035 & 1369 & 3421 & 6845 \\
\hline $\begin{array}{l}\text { SS Cohort } \\
2 \text { (ref) }\end{array}$ & 1713 & 4283 & 8567 & 1692 & 4229 & 8458 & 1663 & 4157 & 8313 & $\begin{array}{l}\text { SS Cohort } \\
2 \text { (ref) }\end{array}$ & 1686 & 4215 & 8429 & 1669 & 4171 & 8343 & 1646 & 4113 & 8226 \\
\hline $\begin{array}{l}\text { CVD } \\
\text { cases }\end{array}$ & 56 & 141 & 283 & 57 & 141 & 282 & 57 & 141 & 282 & $\begin{array}{l}\text { CVD } \\
\text { cases }\end{array}$ & 83 & 207 & 413 & 83 & 207 & 413 & 83 & 207 & 413 \\
\hline$H R$ & 1.00 & 0.98 & 0.96 & 1.01 & 0.97 & 0.97 & 1.02 & 0.98 & 0.98 & $H R$ & 1.11 & 1.08 & 1.07 & 1.11 & 1.09 & 1.08 & 1.11 & 1.09 & 1.08 \\
\hline (SD) & $(0.30)$ & $(0.17)$ & $(0.12)$ & $(0.31)$ & $(0.18)$ & $(0.12)$ & (0.31) & (0.18) & $(0.12)$ & (SD) & $(0.27)$ & $(0.17)$ & $(0.12)$ & $(0.28)$ & $(0.16)$ & $(0.11)$ & $(0.27)$ & $(0.17)$ & $(0.11)$ \\
\hline
\end{tabular}

5-year exposure increases risk of CVD by $0.1 \%$

5-year exposure increases risk of CVD by $5 \%$

Mean values

\begin{tabular}{|c|c|c|c|c|c|c|c|c|c|c|c|c|c|c|c|c|c|c|c|}
\hline $\begin{array}{l}\text { R-M } \\
\text { hazard }\end{array}$ & 1.20 & 1.20 & 1.20 & 1.00 & 1.00 & 1.00 & 0.80 & 0.80 & 0.80 & $\begin{array}{l}\text { R-M } \\
\text { hazard }\end{array}$ & 1.20 & 1.20 & 1.20 & 1.00 & 1.00 & 1.00 & 0.80 & 0.80 & 0.80 \\
\hline Cohort 1 & 1490 & 3724 & 7450 & 1452 & 3631 & 7261 & 1402 & 3506 & 7011 & $\begin{array}{l}\text { SS Cohort } \\
1\end{array}$ & 1357 & 3390 & 6782 & 1338 & 3345 & 6689 & 1314 & 3284 & 5568 \\
\hline $\begin{array}{l}\text { S Cohort } \\
\text { (ref) }\end{array}$ & 1713 & 4281 & 8563 & 1691 & 4227 & 8455 & 1662 & 4155 & 8309 & $\begin{array}{l}\text { SS Cohort } \\
2 \text { (ref) }\end{array}$ & 1648 & 4119 & 8240 & 1635 & 4089 & 8178 & 1618 & 4046 & \\
\hline VD cases & 57 & 143 & 287 & 57 & 143 & 287 & 57 & 144 & 287 & $\begin{array}{l}\text { CVD } \\
\text { cases }\end{array}$ & 118 & 294 & 589 & 118 & 294 & 588 & 118 & 294 & 588 \\
\hline & 1.01 & 0.98 & 0.97 & 1.01 & 0.98 & 0.97 & 1.02 & 0.99 & 0.98 & $H R$ & 1.21 & 1.19 & 1.19 & 1.21 & 1.20 & 1.19 & 1.21 & 1.20 & \\
\hline D) & (030) & 017) & (012) & 030) & 17) & (012) & 030) & (018) & 012) & (SD) & 024) & 015) & 011) & (024) & 015) & 010) & (025) & 015) & \\
\hline
\end{tabular}

5-year exposure increases risk of CVD by $0.5 \%$

5-year exposure increases risk of CDV by $10 \%$

Mean values

\begin{tabular}{|c|c|c|c|c|c|c|c|c|c|c|c|c|c|c|c|c|c|c|c|}
\hline R-M hazard & 1.20 & 1.20 & 1.20 & 1.00 & 1.00 & 1.00 & 0.80 & 0.80 & 0.80 & $\begin{array}{l}\text { R-M } \\
\text { hazard }\end{array}$ & 1.20 & 1.20 & 1.20 & 1.00 & 1.00 & 1.00 & 0.80 & 0.80 & 0.80 \\
\hline SS Cohort 1 & 1482 & 3705 & 7411 & 1445 & 3615 & 7230 & 1398 & 3495 & 6989 & $\begin{array}{l}\text { SS Cohort } \\
1\end{array}$ & 1117 & 27937 & 55867 & 1114 & 2784 & 5567 & 1109 & 2772 & 5544 \\
\hline $\begin{array}{l}\text { SS Cohort } \\
2 \text { (ref) }\end{array}$ & 1709 & 4271 & 8543 & 1688 & 4219 & 8440 & 1660 & 4149 & 8298 & $\begin{array}{l}\text { SS Cohort } \\
2 \text { (ref) }\end{array}$ & 1536 & 3840 & 7681 & 1532 & 3829 & 7657 & 1525 & 3812 & 4 \\
\hline $\begin{array}{l}\text { CVD } \\
\text { cases }\end{array}$ & 61 & 153 & 305 & 61 & 153 & 306 & 61 & 153 & 306 & $\begin{array}{l}\text { CVD } \\
\text { cases }\end{array}$ & 203 & 507 & 015 & 203 & 508 & 1015 & 203 & 507 & \\
\hline$H R$ & 1.03 & 0.99 & 0.98 & 1.03 & 1.00 & 0.99 & 1.03 & 1.01 & 1.00 & $H R$ & 1.48 & 1.47 & 1.47 & 1.48 & 1.47 & 1.47 & 1.48 & 1.47 & 6 \\
\hline D) & $(0.31)$ & $(0.17)$ & $(0.12)$ & $(0.30)$ & $(0.17)$ & $(0.12)$ & $(0.29)$ & $(0.17)$ & $(0.12)$ & (SD) & $(0.23)$ & (0.14) & (0.10) & $(0.23)$ & (0.14) & $(0.10)$ & $(0.23)$ & $(0.14)$ & \\
\hline
\end{tabular}

5 -year exposure increases risk of CVD by $1 \%$

5-year exposure increases risk of CDV by $20 \%$

Mean values

Mean values

\begin{tabular}{|c|c|c|c|c|c|c|c|c|c|c|c|c|c|c|c|c|c|c|c|}
\hline $\begin{array}{l}\text { R-M } \\
\text { hazard }\end{array}$ & 1.20 & 1.20 & 1.20 & 1.00 & 1.00 & 1.00 & 0.80 & 0.80 & 0.80 & $\begin{array}{l}\text { R-M } \\
\text { hazard }\end{array}$ & 1.20 & 1.20 & 1.20 & 1.00 & 1.00 & 1.00 & 0.80 & 0.80 & 0.80 \\
\hline SS Cohort 1 & 1472 & 3679 & 7358 & 1438 & 3592 & 7187 & 1392 & 3479 & 6958 & $\begin{array}{l}\text { SS Cohort } \\
1\end{array}$ & 1482 & 1206 & 2411 & 482 & 1205 & 2412 & 482 & 1206 & 2412 \\
\hline $\begin{array}{l}\text { SS Cohort } \\
2 \text { (ref) }\end{array}$ & 1703 & 4259 & 8517 & 1683 & 4209 & 8418 & 1656 & 4142 & 8283 & $\begin{array}{l}\text { SS Cohort } \\
2 \text { (ref) }\end{array}$ & 1225 & 3064 & 6129 & 1225 & 3061 & 6124 & 1223 & 3057 & 6115 \\
\hline CVD cases & 66 & 165 & 330 & 66 & 165 & 330 & 66 & 165 & 330 & $\begin{array}{l}\text { CVD } \\
\text { cases }\end{array}$ & 254 & 636 & 1272 & 255 & 635 & 1272 & 254 & 636 & 1272 \\
\hline$H R$ & 1.04 & 1.02 & 1.01 & 1.05 & 1.02 & 1.01 & 1.05 & 1.02 & 1.02 & $H R$ & 2.91 & 2.89 & 2.88 & 2.90 & 2.88 & 2.87 & 2.90 & 2.88 & 2.87 \\
\hline SD) & $(0.28)$ & $(0.17)$ & $(0.12)$ & $(0.29)$ & $(0.17)$ & $(0.12)$ & $(0.29)$ & $(0.17)$ & $(0.12)$ & $(S D)$ & (0.38) & $(0.24)$ & $(0.17)$ & $(0.38)$ & $(0.24)$ & $(0.16)$ & $(0.37)$ & $(0.23)$ & $(0.17)$ \\
\hline
\end{tabular}


death) only if they are alive at age $a$. Death can be observed between age $a$ and $a+15$. Censoring occurs for return-migration at an age between $a$ and $a+15$ (end of observation).

Two identical datasets were used but one had all the persons which return-migrated before recruitment (i.e. before age $n$ ) removed from the dataset.

The mortality rate bias due to left-truncation was evaluated using a Cox regression model with group (return-immigrant observed as reference) and age group as independent variables at the end of the observation period. A second Cox model was fitted to adjust for income and education.

Given the models above, the simulations run as follow:

1. For each age group, a dataset is created providing age of death, income, education, and health status, and age of return-migration.

2. It is evaluated whether death and return-migration occurred before, during or after the cohort observation time.

3. For Cohort 1, all those who died or return-migrate before recruitment are removed from observation, while for Cohort 2, only those who died before recruitment are not part of the cohort.

4. The mortality rate ratios between Cohorts 1 and 2 are calculated using a Cox regression model adjusted for age group, and then for income and education.

Biases for migration waves vs. continuous and differential in duration of exposure were evaluated together in the first study. There each scenario was simulated 6000 times to provide reproducible results. For the second simulation study (return-migration alone) each scenario was simulated 10000 times reflecting that the models have more variability. The simulations were performed with R [18] using the package Survival [19].

\section{Results}

\section{Comparing populations from migration waves vs.} continuous migration

Age-adjusted bias due to not controlling for the differences in migration patterns is presented in Table 1 with mean hazard-ratios for CVD between the two cohorts. As long as exposure duration to the host country plays no role in the risk of CVD, then there is virtually no bias due to the different types of migration.

\section{Differentials in duration of exposure to the host country}

The size of the two cohorts depends on the overall risk for CVD (Table 1) because only immigrants who did not have CVD before recruitment could be recruited. For increases in risk of CDV of less than $1 \%$ every 5 years, there is virtually no bias. With $1 \%$ increased CDV risk there is a bias of between 1 and 5\%. If the duration of exposure to the host country increases the hazard of CVD by $5 \%$ every 5 year, then the risk of CVD for the cohort with the longest exposure pre-recruitment (wave migration) was $20 \%$ higher than for the cohort with continuous migration (reference). This raises to about $47 \%$ if the hazard due to exposure increases by $10 \%$ and is almost 3 times (HR 2.87-2.91) higher if the hazard increases by $20 \%$ for 5 -year exposure.

\section{Selective return-migration}

Results are given in Table 2 and the distributions of the age-adjusted MRR are presented using boxplots in Fig. 2 for both the unadjusted and adjusted rates.

As expected the number of censored observations and the number of observed deaths vary between the models. The ratio of observed death to the total number of observations is about $17 \%$ for Model 1 for the populations with and without left-truncation, for Model 2 these are 15 and 17\% respectively, for Model 3 again about 17\% for both populations and for Model 4, 12 and 14\% respectively.

The MRR bias ranged from $8.5 \%$ overestimation of the MRR in Model 3, 6.3\% overestimation in Model 1, 5.5\% underestimation in Model 3 to $8.5 \%$ underestimation in Model 4.

Adjusting for two known factors predicting returnmigration has varied effects on the MRR (Fig. 2). It removes the MRR bias in Model 1 and 2. In Model 3 and 4 for which these two factors are not the only predictors, adjusting reduced the bias for Model 3 but changed the direction and did increase the bias for Model 4 from 8.5 to $16.3 \%$.

\section{Discussion}

Estimating the effect of integration policies on the health of migrant populations requires international comparison. But migrant populations included in those comparisons may have been constituted according to different migration mechanisms occurring before the observation started. We have simulated data in order to isolate the effects of differentials in migration patterns with the aim to investigate the possibilities of bias due to these differentials.

We considered the role of differential in wave vs. continuous migration, duration of exposure to the host country, and return-migration. We have seen that two factors - duration of exposure to the host country and selective return-migration - can lead to bias that even well designed cohort studies cannot avoid. The order of magnitude of the bias we obtained could be the same as those effects seen in the literature and interpreted as due to integration policies. 
Table 2 Age adjusted mortality rate ratios (MRR) bias for the four models. All results are the mean taken over the 10000 simulations

\begin{tabular}{|c|c|c|c|c|}
\hline Model & Observed deaths ${ }^{*}$ (\% of all obs.) & Observed $\mathrm{RM}^{*}$ & Censored observations $^{*}$ & $\begin{array}{l}\text { MRR Bias (SD) } \\
\text { a. unadj., b. adj.. }\end{array}$ \\
\hline \multicolumn{5}{|c|}{ Model 1} \\
\hline & 3458 (17\%) & - & 16621 & a. 1.063 (0.009) \\
\hline & $2829(17 \%)$ & - & 13024 & b. $1.000(0.008)$ \\
\hline \multicolumn{5}{|c|}{ Model 2} \\
\hline & 3348 (15\%) & 892 & 15838 & a. $0.944(0.007)$ \\
\hline & 2725 (17\%) & 892 & 15156 & b. 0.995 (0.008) \\
\hline \multicolumn{5}{|c|}{ Model 3} \\
\hline & 3383 (17\%) & 464 & 16233 & a. $1.085(0.011)$ \\
\hline & 2829 (17\%) & 464 & 12197 & b. 0.977 (0.010) \\
\hline \multicolumn{5}{|c|}{ Model 4} \\
\hline & 2888 (12\%) & 1240 & 15950 & a. $0.915(0.013)$ \\
\hline & 1814 (14\%) & 1240 & 11900 & b. 0.837 (0.011) \\
\hline
\end{tabular}

*The values in italics are for the population with return migration observed

${ }^{* *}$ Adjusted for income and education level

\section{Exposure to the host country}

Assuming that the duration of exposure to the host country has a dose-response effect, not accounting for it may lead to bias. And this bias is particularly strong if one population has migrated in a wave and the other continuously because the duration of exposures are more likely to differ. Yet during on-going wave migration (e.g. refugees of current conflicts) the exposure to policies might be short but with far-reaching effects by restricting access to health care for example. Controlling for duration alone (for example by including year of arrival in the regression model) is therefore not sufficient; the actual policies to which one has been exposed are also relevant.

Comparing the effect of integration policies between countries [3] should also involve the actual years when these policies were put in place and the actual duration of exposure pre-recruitment to these policies using the like of the Migrant Integration Policy Index MIPEX [20] to take into account changes in policies over time. Not doing so is likely to lead to false interpretations about the actual effect of these policies.

Moreover, populations may experience multiple migration between their country of birth and a host country. For example, Polish migrants returned to Poland and then migrated back to a target country [21]. Similar patterns of return and subsequent reentry have been observed elewhere [22]. Transnational activities (see Carling and Erdal [23] for a definition) also play an important role in particular to evaluate a "true" exposure to the host country which is not just a question of time but also of intensity which needs to be determined.

\section{Models for return-migration}

Bias due to left-truncation can be avoided if the duration of exposure and models for return-migration patterns
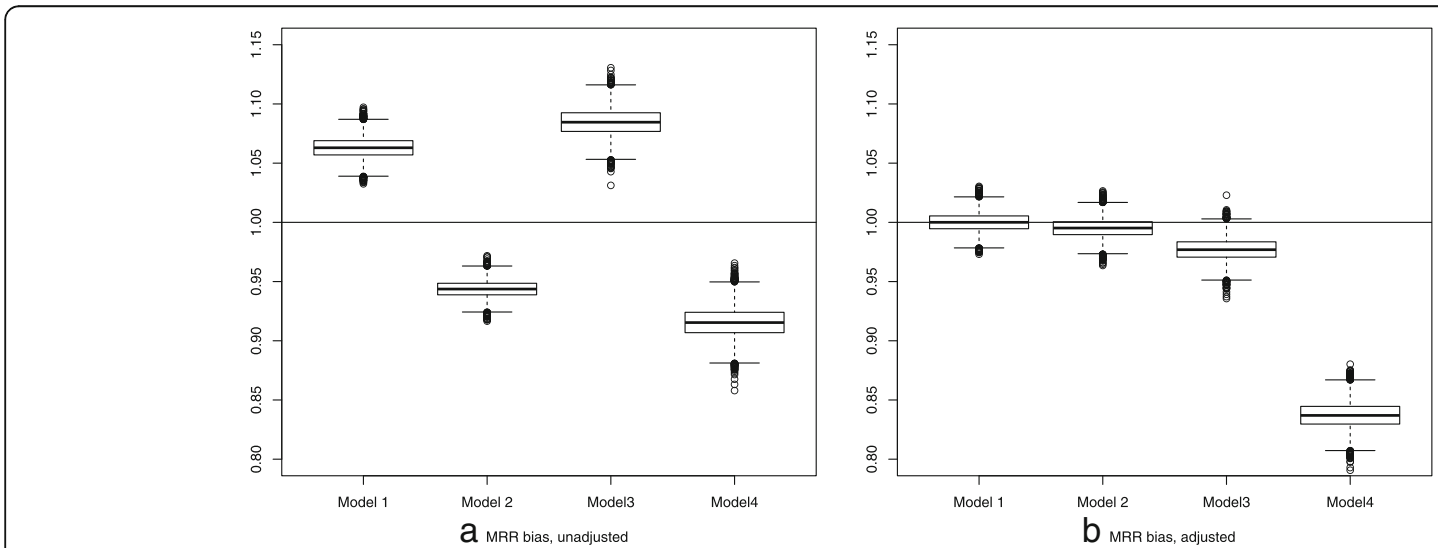

Fig. 2 Box plots of mortality rate ratio (MRR) bias unadjusted (a) and adjusted for income and education (b) 
are known. Because methods to control for lefttruncation involve inverse probability weighting [24, 25], probabilities to have return-migrated at the time of recruitment given a range of covariates need to be known. The simplifying model used in the simulation study has shown that even simple return-migration mechanisms can lead to biased estimates of relative mortality between countries. In other research contexts, the need for more or better research about return-migration has already been highlighted ([26], "current research has been limited to studying the return of adult men and their insertion into labor markets" [27]] and a wide range of factors leading to return-migration have been presented in the literature. These potential causes are not easy to operationalize but nonetheless quantitative models for return-migration should be proposed to properly control for left-truncation. A particular attention should be paid to retired immigrants who spend parts of the year in their country of birth without permanently re-migrating (a phenomenon often described as "pendulum migration").

It is neither always necessary nor sensible to control for all return-migration occurring before recruitment into a cohort. For example, if a cohort of older people is recruited and the comparison in mortality is the outcome of interest, it might not be necessary to control for the return-migration of young, newly qualified immigrants.

\section{Conclusion}

The order of magnitude of differences in health outcomes reported in the literature comparing country policies towards immigrants is similar to that of the bias obtained in our simulations due to differentials between countries in return-migration or duration of exposure before being observed. Thus, conclusions like those drawn by Malmusi ([3],) and Ikram [4] about the differences reported in risk of poor health depending on integration policy may constitute an over-interpretation. Taking into account duration and relevance of exposure and left-truncation due to return-migration is compulsory to make valid inferences about the effects of integration policies on the health of immigrants. In order to do so, indicators of integration policies over time need to be used and quantitative models for return-migration developed. These conclusions are relevant even for welldesigned cohort studies.

\section{Additional file}

Additional file 1: Table of probabilities of return-migration (RM) for the second simulation study by age group (1. between 25 and 35 year, 2. between 63 and 67 year and 3. on average 3 years (0.5) before death) for each model. (PDF $59 \mathrm{~kb}$ )

\section{Abbreviations}

CVD: Cardiovascular disease; MIPEX: Migrant Integration Policy Index; MRR: Mortality rate ratio

\section{Acknowledgements}

This work has been presented at the EUPHA Conference in November 2017 [28].

\section{Authors' contributions}

OR and OS have conceptualized the study. OS designed and performed the simulation. OS and OR wrote the article. Both authors have read and approved the manuscript.

\section{Funding}

No funding has been received for this work.

Availability of data and materials

Our simulation code used during the current study is available from the corresponding author on reasonable request.

Ethics approval and consent to participate

No Ethical approval was necessary because no real data was used

(simulation study).

Consent for publication

Not applicable.

\section{Competing interests}

The authors declare that they have no competing interest.

Received: 29 January 2019 Accepted: 30 June 2019

Published online: 09 July 2019

\section{References}

1. Mackenbach JP, Stirbu I, Roskam A-JR, Schaap MM, Menvielle G, Leinsalu M, Kunst AE. Socioeconomic inequalities in health in 22 European countries. $N$ Engl J Med. 2008;358(23):S. 2468-81.

2. Bhopal RS, Rafnsson SB, Agyemang C, Fagot-Campagna A, Giampaoli S, Hammar N, et al. Mortality from circulatory diseases by specific country of birth across six European countries. Test of concept. Eur J Public Health. 2012;22(3):S. 353-9.

3. Malmusi D. Immigrants' health and health inequality by type of integration policies in European countries. Eur J Pub Health. 2014;25(2): 293-9 April 2015.

4. Ikram UZ, Malmusi D, Juel K, Rey G, Kunst AE. Association between integration policies and immigrants' mortality. An explorative study across three european countries. PLoS One. 2015;10(6):e0129916.

5. Castles S. The forces driving global migration. J Intercult Stud. 2013;34(2): 122-40.

6. Handlos LN, Olwig KF, Bygbjerg IC, Kristiansen M, Norredam ML. Return migration among elderly, chronically ill Bosnian refugees. Does health matter? Int J Environ Res Public Health. 2015;12(10):12643-61. https://doi. org/10.3390/ijerph121012643.

7. Razum O, Sahin-Hodoglugil NN, Polit K. Health, wealth or family ties? Why Turkish work migrants return from Germany. J Ethn Migr Stud. 2005;31(4):S. 719-39.

8. Buergin A, Erzene-Buergin D. Educated in Germany, working in Turkey. The Emigration Motivations of Persons of Turkish Origin. Ger Politics. 2013;22(4): S. 461-76. https://doi.org/10.1080/09644008.2013.853042.

9. Erdal MB, Amjad A, Bodla QZ, Rubab A. Going Back to Pakistan for education? The interplay of return Mobilities, education, and transnational living. Popul Space Place. 2016;22(8):836-48. https://doi. org/10.1002/psp.1966

10. Vandenbroucke JP, Pearce N. Incidence rates in dynamic populations. Int J Epidemiol. 2012;41(5):S. 1472-9.

11. Abraido-Lanza AF, Dohrenwend BP, Ng-Mak DS, Turner JB. The Latino mortality paradox. A test of the "salmon bias" and healthy migrant hypotheses. Am J Public Health. 1999;89(10):S. 1543-8.

12. Arenas E, Goldman N, Pebley AR, Teruel G. Return migration to Mexico. Does health matter? Demography. 2015;52(6):1853-68. https://doi.org/10.1 007/s13524-015-0429-7 
13. Norredam M, Hansen OH, Petersen JH, Kunst AE, Kristiansen M, Krasnik A, Agyemang C. Remigration of migrants with severe disease. Myth or reality?--a register-based cohort study. Eur J Public Health. 2015 Feb;25(1):S. 84-9.

14. Klein JP, Moeschberger ML. Survival analysis. Techniques for censored and truncated data: Springer Science \& Business Media. New York: SpringerVerlag; 2005. https://doi.org/10.1007/978-1-4757-2728-9.

15. Applebaum KM, Malloy EJ, Eisen EA. Left truncation, susceptibility, and bias in occupational cohort studies. Epidemiology. 2011;22(4):S. 599.

16. Cain KC, Harlow SD, Little RJ, Nan B, Yosef M, Taffe JR, Elliott MR. Bias due to left truncation and left censoring in longitudinal studies of developmental and disease processes. Am J Epidemiol. 2011;173(9):1078-84 kwq481.

17. Statistisches-Bundesamt (2017): Sterbefälle, Lebenserwartung.

18. R Core Team. R: A language and environment for statistical computing. Vienna: R Foundation for Statistical Computing; 2018. https:/wwww.R-project.org/.

19. Therneau, Terry M. (2015): A package for survival analysis in S. https://CRAN. R-project.org/package=survival

20. Meuleman B, Reeskens T. The relation between integration policy and majority attitudes toward immigration. An empirical test across European countries. In: Dag van de Sociologie, Leuven; 2008. Available at: http//soc. kuleuven. be/ ceso/dagvandesociologie/papers/IntegrationPolicy\&Attitudes. pdf.

21. White A. Double return migration. Failed returns to Poland leading to settlement abroad and new transnational strategies. Int Migr. 2014;52(6):7284. https://doi.org/10.1111/imig.12138 .

22. Vega A, Brazil N. A multistate life table approach to understanding return and reentry migration between Mexico and the United States during later life. Demogr Res. 2015;33:S. 1211-40. https://doi.org/10.4054/DemRes.2 015.33.43.

23. Carling J, Erdal MB. Return migration and transnationalism. How are the two connected? Int Migr. 2014;52(6):2-12. https://doi.org/10.1111/imig.12180

24. Howe CJ, Cole SR, Chmiel JS, Muñoz A. Limitation of inverse probability-ofcensoring weights in estimating survival in the presence of strong selection bias. Am J Epidemiol. 2011;173(5):S. 569-77.

25. Seaman SR, White IR. Review of inverse probability weighting for dealing with missing data. Stat Methods Med Res. 2013;22(3):278-95.

26. Riosmena F. The potential and limitations of cross-context comparative research on migration. Ann Am Acad Pol Soc Sci. 2016;666(1):28-45

27. Sandoval R, Zuniga V. Who are returning from the United States to Mexico?: a review criticizes of the recent literature (2008-2015). Mex Stud Estud Mex. 2016;32(2):328-56.

28. O Sauzet, O Razum. Bias in assessing the effect of integration policies by comparing migrant health between countries: Odile Sauzet. Euro J Pub Health. 2017;27(suppl_3):ckx187.124. https://doi.org/10.1093/eurpub/ckx1 87.124.

\section{Publisher's Note}

Springer Nature remains neutral with regard to jurisdictional claims in published maps and institutional affiliations.

\section{Ready to submit your research? Choose BMC and benefit from:}

- fast, convenient online submission

- thorough peer review by experienced researchers in your field

- rapid publication on acceptance

- support for research data, including large and complex data types

- gold Open Access which fosters wider collaboration and increased citations

- maximum visibility for your research: over $100 \mathrm{M}$ website views per year

At $\mathrm{BMC}$, research is always in progress.

Learn more biomedcentral.com/submissions 